Conclusions: The IR of ADRwas $16.2 \%$, being similar in all age categories Gastrointestinal was the main cause of ADR followed by infections. We have found differences in discontinuation rates among DMARD due to ADR, being Abatacept, Gold and Leflunomide the drugs with the highest risk. Methotrexate had a lower risk of ADR compared to other DMARD. Caution should be taken in patients receiving combined therapy and with certain comorbidities

Disclosure of Interest: None declared

DOI: 10.1136/annrheumdis-2018-eular.2473

Saturday, 16 JUNE 2018

Rheumatoid arthritis - biological DMARDs

\section{SAT0165 REASONS FOR BDMARD CESSATION AND SUBSEQUENT PERSISTENCE OF SECOND LINE TREATMENT IN A LARGE REAL WORLD RHEUMATOID ARTHRITIS REGISTRY}

P. Youssef ${ }^{1}$, B. Marcal $\left.\right|^{2}$, P. Button ${ }^{3}$, M. Truman ${ }^{3}$, P. Bird ${ }^{4}$, H. Griffiths ${ }^{5}$, L. Roberts ${ }^{6}$, K. Tymms ${ }^{7}$, G. Littlejohn ${ }^{8} .{ }^{1}$ Royal Prince Alfred Hospital, Camperdown, ${ }^{2}$ Roche Products, Pty. Limited, ${ }^{3} \mathrm{OzB}$ Biostat Pty. Ltd., ${ }^{4}$ University of New South Wales, Sydney, ${ }^{5}$ Barwon Rheumatology Service, Geelong, ${ }^{6}$ Monash Rheumatology, Clayton, ${ }^{7}$ Canberra Rheumatology, Canberra, ${ }^{8}$ Monash University, Clayton, Australia

Background: The current recommendations for treating Rheumatoid Arthritis (RA) patients (pts) who fail on conventional disease modifying anti-rheumatic drugs (DMARDs) is to use biologic (b) or targeted synthetic (ts) DMARDs. Pts who fail first (1st) line b/tsDMRADs are recommended to go on other b/tsDMARDs; however, reasons for stopping or switching between bDMARDs according to mode of action and the persistence on treatment are not well characterized in real world patient populations.

Objectives: The primary objective was to identify the reasons for stopping 1st line b/tsDMARDs in RA pts treated in the clinical practice setting. The secondary objectives were to identify second (2nd) line b/tsDMARDs choices in pts who stop TNF inhibitors (TNFis) within 6 months (mo) due to lack of efficacy and the persistence on these treatments.

Methods: Pts $\geq 18$ years with confirmed RA who were treated with 1 st line b/ tsDMARDs, from 1 August 2010 to 30 June 2017, by physicians participating in the OPAL-QUMI database, were included in the analyses. Reasons for stopping $\mathrm{b} / \mathrm{tsDMARD}$ s were recorded by the treating physician during routine visits. The following b/tsDMARDs were included abatacept (ABA), adalimumab, certolizumab pegol, etanercept, golimumab, infliximab and tocilizumab (TCZ), rituximab (RTX) and tofacitinib (TFB). Data were analysed using descriptive statistics for continuous variables and frequency counts for categorical variables. Persistence on treatment was summarised using Kaplan-Meier (K-M) methodology. Individual TNFis were combined for simplicity.

Abstract Sat0165 - Table 1. Patients receiving 1st line treatment by mechanism of action.

\begin{tabular}{|c|c|c|c|c|c|}
\hline First-line Treatment & RTX & TCZ & TFB & ABA & TNFis \\
\hline Started, $\mathbf{n}$ & 230 & 555 & 518 & 609 & 5002 \\
\hline Stopped, n(\%) & $51(22)$ & $238(43)$ & $105(20)$ & $233(38)$ & $2029(41)$ \\
\hline Stopped within 6 months; $\mathrm{n}(\%)^{z}$ & $11(22)^{*}$ & $41(17)^{5 *}$ & $57(54)$ & $72(31)^{5}$ & $733(36)^{*}$ \\
\hline \multicolumn{6}{|c|}{ percentage relative to subset stopped treatment } \\
\hline \multicolumn{6}{|c|}{${ }^{*} \mathrm{p}<0.001: \mathrm{RTX}$ vs TFB; TCZ vs ABA; TNFis vs TFB } \\
\hline
\end{tabular}

Abstract Sat0165 - Table 2 K-M. estimates of persistence on 2nd line b/tsDMARDs after discontinuation of 1 st line TNFis due to lack of efficacy.

\begin{tabular}{|c|c|c|c|c|c|}
\hline & RTX & $\mathrm{TCZ}$ & TFB & $\mathrm{ABA}$ & TNFis \\
\hline $\mathrm{N}$ & 13 & 49 & 25 & 92 & 130 \\
\hline 6 months, \% & 75 & 78 & 71 & 61 & 60 \\
\hline 12 months, $\%$ & 75 & 57 & ND & 49 & 40 \\
\hline
\end{tabular}

Results: A total of 6914 pts received 1st line b/tsDMARDs. Median age was 61 years, median disease duration (RA onset to last visit) was 10 years. The majority
(75\%) were females. Treatment was stopped in 2656 pts (38\%); 914 (34\%) of these stopped within 6 mo of treatment initiation. The highest and lowest percentage of pts stopping treatment within 6 mo was in pts receiving TFB (54\%) and TCZ (17\%), respectively (table 1). The most common reasons for stopping therapy within 6 mo were lack of efficacy (45\%>ABA, 44\%>TNFis, 33\%>TFB and $27 \%>$ TCZ) and adverse reactions (21\%>TFB, 20\%>TCZ, $15 \%>$ TNFis, $13 \%$ $>A B A)$. Stopping due to lack of efficacy-primary failure was highest for TFB $(23 \%)$. The percentage of pts remaining on 2 nd line b/tsDMARD treatment after stopping 1 st line TNFis due to lack of efficacy was the highest for TCZ (78\%) at 6 mo and RTX (75\%) at 12 mo (table 2). Median time to stopping 2 nd line treatment was $48 \mathrm{mo}(95 \% \mathrm{Cl}: 17-74)$ for RTX, $21 \mathrm{mo}$ (95\% Cl:11-62) for TCZ, $21 \mathrm{mo}$ (95\% $\mathrm{Cl}: 6-21)$ for TFB; $11 \mathrm{mo}$ (95\% Cl:8-22) for ABA and 9 mo (95\% Cl:7-12) TNFis. Conclusions: The primary failure rate is lower than previously reported. In pts who failed 1st line TNFis within 6 mo of commencement due to lack of efficacy 2nd line TNFis resulted in the lowest treatment persistence. These real world data will assist clinicians with treatment choices post primary TNFis failure.

Acknowledgements: Sponsored by Roche Products, Pty. Limited. Medica Writing provided by Dr Joseline Ojaimi from Roche.

Disclosure of Interest: P. Youssef: None declared, B. Marcal Employee of: Roche Products, Pty. Limited, P. Button Consultant for: Roche Products, Pty. Limited, M. Truman Consultant for: Roche Products, Pty. Limited, P. Bird: None declared, H. Griffiths: None declared, L. Roberts Consultant for: AbbVie, BristolMyers Squibb, Janssen, Pfizer, Roche Products, Pty. Limited, UCB, K. Tymms Consultant for: AbbVie, Bristol-Myers Squibb, Janssen, Pfizer, Roche Products, Pty. Limited, UCB, G. Littlejohn Consultant for: AbbVie, Bristol-Myers Squibb, Janssen, Pfizer, Roche Products, Pty. Limited, UCB

DOI: 10.1136/annrheumdis-2018-eular.6022

\section{SAT0166 WHICH BIOLOGIC AGENT IS MOST SUITABLE FOR AN EXTENDED-INTERVAL TREATMENT FOR RHEUMATOID ARTHRITIS ? RESULTS FROM A MULTICENTER STUDY}

K. Katayama ${ }^{1}$, H. Matsuno ${ }^{2}$, T. Matsubara ${ }^{3} .{ }^{1}$ Orthopedic Surgery, Katayama Orthopedic Rheumatology Clinic, Asahikawa, ${ }^{2}$ Orthopedic Surgery, Matsuno Clinic for Rheumatic Diseases, Toyama, ${ }^{3}$ Orthopedic Surgery, Matsubara Mayflower Hospital, Kobe, Japan

Background: Biological disease-modifying antirheumatic drugs (bDMARDs) have made apparent development of treating rheumatoid arthritis (RA). However, prescription of them appeared to be relatively difficult due to high cost. The newest EULAR recommendation advocates tapering of bDMARDs when RA activity is controlled.

Objectives: A multicenter clinical study on a longer interval treatment with three bDMARDs, Golimumab (GOL), which is one of TNF inhibitors, and two of nonTNF inhibitor, Tocilizumab (TCZ) and Abatacept (ABT) was investigated.

Methods: Patients, who were maintained at low disease activity by DAS28 score for more than 3 months treated with GLM, TCZ, ABT, were enrolled. These selected patients were treated with these drugs with 1.5 fold longer interval of standard schedule for 60 weeks, and the rate of patients, who preserved low dis ease activity were determined. The patients who were not tolerated these drugs because of the side effects or adverse events, were withdrawn from this study.

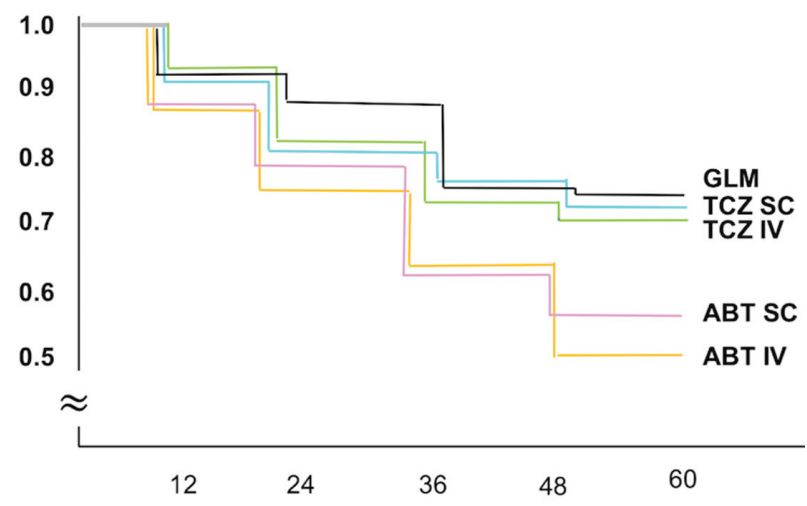

Results: One hundred thirty-one patients treated with GLM, 149 with ABT (S.C 61, I.V. 88) and 299 with TCZ (S.C. 87, I.V. 212) were enrolled. Among these, 57 patients treated with GLM (43\%), 40 with ABT(26\%, S.C 18, I.V 22), 93 with TCZ $(31 \%$, S.C 21, I.V 72$)$ were successfully maintained at low disease activity with 
this 1.5 folds longer interval treatment, respectively. The age of patients in ABT group was $73.5 \pm 10.6$, and significantly higher than those in TCZ $(58.8 \pm 13.9)$ and GOL (58.1 \pm 14.7$)$ groups. At 60 weeks, DAS28 in ABT group was $3.1 \pm 0.5$, and significantly higher than those in TCZ $(2.6 \pm 0.7)$ and GLM $(2.6 \pm 0.7)$ groups. On the other hand, CDAI in GOL was 6.6 \pm 3.4 , and was significantly higher than those in TCZ $(4.4 \pm 2.6)$ or ABT $(4.6 \pm 2.3)$ groups. Accordingly, successive rate at 60th week in ABT group was $52 \%$ and significantly lower than those in TCZ $(69 \%)$ or in GOL $(73 \%)$ groups as shown in figure. Finally, no significant difference in successive rate was observed between s.c. and i.v.

Conclusions: This study clarified that TCZ and GLM had higher successive rate than ABT for maintaining low disease activity for 60 weeks by longer interval treatment. This effectiveness might relate to the high therapeutic efficacy of TCZ and low antigenicity of GOL.

Disclosure of Interest: None declared

DOI: 10.1136/annrheumdis-2018-eular.1464

\section{SAT0167 COMPARISON OF THE EFFICACY AND TOLERABILITY OF TOCILIZUMAB, SARILUMAB, AND SIRUKUMAB IN PATIENTS WITH ACTIVE RHEUMATOID ARTHRITIS: A BAYESIAN NETWORK META-ANALYSIS OF RANDOMIZED CONTROLLED TRIALS}

Y. H. Lee ${ }^{1}$, Y. H. Seo ${ }^{1} .{ }^{1}$ Rheumatology, Korea University Medicial Center, Seoul, Korea, Republic Of

Background: A humanized, anti-human IL-6 receptor monoclonal antibody, tocilizumab, was developed to block IL- 6 signaling and has been used as an effective therapeutic agent for patients that do not respond to methotrexate (MTX) or tumor necrosis factor (TNF) inhibitor. The successful use of tocilizumab in RA stimulated the development of other biologics targeted to the IL-6 pathway, such as anti-IL6R (sarilumab) or anti-IL-6 (sirukumab) antibodies

Objectives: The relative efficacy and tolerability of tocilizumab, sarilumab, and sirukumab were assessed in patients with rheumatoid arthritis (RA) and an inadequate response to MTX or TNF inhibitors.

Methods: We performed a Bayesian network meta-analysis to combine direct and indirect evidence from randomized controlled trials (RCTs) to examine the efficacy and safety of tocilizumab, sarilumab, and sirukumab in RA patients and an inadequate MTX or TNF inhibitor response.

Results: Fourteen RCTs, comprising 9,753 patients, met the inclusion criteria. Tocilizumab $8 \mathrm{mg}$ combined with MTX or as monotherapy was the most effective treatment for active RA with an inadequate MTX or TNF antagonist response, followed by sarilumab and sirukumab, regardless of MTX combination. The ranking probability based on the surface under the cumulative ranking curve (SUCRA) indicated that tocilizumab $8 \mathrm{mg}+\mathrm{MTX}$ had the highest probability of being the best treatment to achieve the ACR50 response rate, followed by tocilizumab $8 \mathrm{mg}$, sarilumab $200 \mathrm{mg}$, sarilumab $200 \mathrm{mg}+\mathrm{MTX}$, sirukumab $100 \mathrm{mg}$, tocilizumab $4 \mathrm{mg}$ +MTX, sirukumab $100 \mathrm{mg}+\mathrm{MTX}$, sirukumab $50 \mathrm{mg}+\mathrm{MTX}$, sarilumab $150 \mathrm{mg}$ +MTX, adalimumab $40 \mathrm{mg}$, and sirukumab $50 \mathrm{mg}$, and placebo+MTX. No significant differences were observed in withdrawals owing to adverse events after treatment with tocilizumab $8 \mathrm{mg}+\mathrm{MTX}$, sirukumab $100 \mathrm{mg}+\mathrm{MTX}$, or sarilumab $200 \mathrm{mg}+$ MTX.

Conclusions: In RA patients with an inadequate MTX or anti-TNF therapy response, tocilizumab $8 \mathrm{mg}$ as monotherapy and combined with MTX showed acceptable tolerability and the highest performance based on the ACR50 response rate, followed by sarilumab and sirukumab.

\section{REFERENCES:}

[1] Smolen JS, Beaulieu A, Rubbert-Roth A, Ramos-Remus C, Rovensky J, Alecock E, Woodworth T, Alten R, Investigators O. Effect of interleukin-6 receptor inhibition with tocilizumab in patients with rheumatoid arthritis (OPTION study): a double-blind, placebo-controlled, randomised trial. The Lancet 2008;371:987-997.

[2] Genovese M, Fleischmann R, Fiore S, Radin A, Fan C, Huizinga T. SAT0117 Sarilumab, a Subcutaneously-Administered, Fully-Human Monoclonal Antibody Inhibitor of The IL-6 Receptor: Relationship Between Eular Responses and Change from Baseline of Selected Clinical Parameters. Annals of the Rheumatic Diseases 2013;72:A620-A620.

[3] Xu Z, Bouman-Thio E, Comisar C, Frederick B, Van Hartingsveldt B, Marini JC, Davis HM, Zhou H. Pharmacokinetics, pharmacodynamics and safety of a human anti-IL-6 monoclonal antibody (sirukumab) in healthy subjects in a first-in-human study. British journal of clinical pharmacology 2011;72:270-281

Disclosure of Interest: None declared DOI: 10.1136/annrheumdis-2018-eular.1644

\section{SAT0168 MRI RESULTS FOLLOWING DISCONTINUATION OF METHOTREXATE IN PATIENTS WITH RHEUMATOID ARTHRITIS TREATED WITH SUBCUTANEOUS TOCILIZUMAB: RESULTS FROM A RANDOMIZED CONTROLLED TRIAL}

C. Peterfy ${ }^{1}$, J. Kremer ${ }^{2}$, W. Rigby ${ }^{3}$, N. Singer ${ }^{4}$, C. Birchwood ${ }^{5}$, D. Gill ${ }^{5}$, W. Reiss ${ }^{5}$, J. Pei ${ }^{5}$, M. Michalska ${ }^{5} .{ }^{1}$ Spire Sciences, Inc., Boca Raton, ${ }^{2}$ Albany Medical College and The Center for Rheumatology, Albany, ${ }^{3}$ Geisel School of Medicine, Dartmouth College, Lebanon, ${ }^{4}$ Case Western Reserve University and the MetroHealth System, Cleveland, ${ }^{5}$ Genentech, Inc., South San Francisico, United States

Background: Although previous studies have established the efficacy of tocilizumab (TCZ) initiated as monotherapy (MONO) for the treatment of rheumatoid arthritis (RA) ${ }^{1,2}$ changes in active intra-articular inflammation after discontinuation of methotrexate (MTX) in patients achieving good clinical control with TCZ + MTX have not been evaluated. Magnetic resonance imaging (MRI) effectively images synovitis and osteitis and can detect changes in bone erosion with greater sensitivity than radiography. ${ }^{3}$

Objectives: This study used MRI to assess differences in joint damage between patients with RA who achieved low disease activity with TCZ + MTX and then continued or discontinued MTX in the COMP-ACT trial (NCT01855789).

Methods: US patients with RA who were inadequate responders to MTX were enrolled; initial combination therapy included MTX ( $>15 \mathrm{mg} /$ week orally) plus TCZ $162 \mathrm{mg}$ subcutaneous (SC) either weekly or every 2 weeks. Patients who achieved DAS28-ESR $\leq 3.2$ at week 24 were randomized 1:1 to receive TCZMONO or continue TCZ + MTX until week 52 (double blind). A subset of these patients was included in this MRI substudy; 1.5 Tesla MRI was used to obtain images of bilateral hands and wrists at Weeks 24 and 40 . Two independent radiologists evaluated images at a central reading facility using RAMRIS (synovitis, osteitis, erosion) and CARLOS (cartilage loss). Outcomes included changes in MRI scores from Week 24 to 40 and the proportion of patients with progression of each score.

Results: Of the 296 patients who achieved DAS28 $\leq 3.2$ at Week 24 and were randomized to TCZ + MTX or TCZ-MONO, 79 were enrolled in the MRI substudy $(n=41$ and 38 , respectively); $74.7 \%$ were women, and the mean (SD) age was 56.3 (12.8) years. Patient demographics in the MRI substudy were similar to overall study demographics. Mean changes from Week 24 to 40 in bone erosion, synovitis, osteitis and cartilage loss scores were not significantly different between the TCZ + MTX and TCZ-MONO groups for both bilateral hands and the dominant hand (table 1). There were no significant differences between the groups in the proportion of patients with no progression in each outcome measure (range, $89.7 \%$ to $97.4 \%$ with TCZ + MTX and $87.9 \%$ to $100.0 \%$ with TCZ-MONO).

Table 1 MRI Changes in Patients Receiving TCZ in Combination With MTX or TCZ as Monotherapy

\begin{tabular}{|c|c|c|c|c|c|c|}
\hline \multirow[b]{2}{*}{$\begin{array}{l}\text { Mean change } \\
\text { from Week } 24 \\
\text { to } 40^{*}\end{array}$} & \multicolumn{3}{|c|}{ Both Hands } & \multicolumn{3}{|c|}{ Dominant Hand } \\
\hline & $\begin{array}{c}\mathrm{TCZ}+\mathrm{MTX} \\
(\mathrm{n}=41)\end{array}$ & $\begin{array}{c}\text { TCZ-MONO } \\
(\mathrm{n}=38)\end{array}$ & $\begin{array}{l}\text { Difference } \\
\text { (95\% CI) (TCZ- } \\
\text { MONO minus } \\
\text { TCZ + MTX) }\end{array}$ & $\begin{array}{c}\mathrm{TCZ}+\mathrm{MTX} \\
(\mathrm{n}=41)\end{array}$ & $\begin{array}{c}\text { TCZ-MONO } \\
(n=38)\end{array}$ & $\begin{array}{c}\text { Difference } \\
\text { (95\% CII) (TCZ- } \\
\text { MONO minus } \\
\text { TCZ + MTX) }\end{array}$ \\
\hline $\begin{array}{l}\text { Bone erosion } \\
\text { score (0-250), } \\
\text { mean (SE) }\end{array}$ & $-0.06(0.18)$ & $0.18(0.19)$ & $\begin{array}{c}0.24 \\
(-0.21 \text { to } 0.68)\end{array}$ & $0.06(0.24)$ & $0.49(0.25)$ & $\begin{array}{c}0.43 \\
(-0.14 \text { to } 1.01)\end{array}$ \\
\hline $\begin{array}{l}\text { Synovitis score } \\
(0-24) \text {, mean } \\
\text { (SE) }\end{array}$ & $-0.24(0.15)$ & $-0.18(0.15)$ & $\begin{array}{c}0.06 \\
(-0.30 \text { to } 0.41)\end{array}$ & $-0.22(0.12)$ & $-0.11(0.12)$ & $\begin{array}{c}0.11 \\
(-0.18 \text { to } 0.40)\end{array}$ \\
\hline $\begin{array}{l}\text { Osteitis score } \\
\text { (0-75), mean } \\
\text { (SE) }\end{array}$ & $-0.16(0.34)$ & $0.37(0.36)$ & $\begin{array}{c}0.53 \\
(-0.30 \text { to } 1.36)\end{array}$ & $-0.39(0.52)$ & $0.69(0.54)$ & $\begin{array}{c}1.07 \\
(-0.18 \text { to } 2.33)\end{array}$ \\
\hline $\begin{array}{l}\text { Cartilage loss } \\
\text { score (0-100). } \\
\text { mean (SE) }\end{array}$ & $0.20(0.14)$ & $-0.03(0.15)$ & $\begin{array}{c}-0.23 \\
(-0.58 \text { to } 0.11)\end{array}$ & $0.11(0.18)$ & $-0.05(0.19)$ & $\begin{array}{c}-0.16 \\
(-0.59 \text { to } 0.27)\end{array}$ \\
\hline
\end{tabular}

MTX, methotrexate; TCZ, tocilizumab; TCZ-MONO, TCZ monotherapy.

"ANCOVA model for estimated means includes Week 24 bone erosion as a covariate, treatment group and the randomization stratification factors: DAS28 remission status at Week $24(<2.6,22.6$ to $\leq 3.2)$, patient anti-TNF exposure
(Yes or No) and baseline weight-by-dosing group ( $<80 \mathrm{~kg} \mathrm{q2w,} 80$ to $<100 \mathrm{~kg}$ q2w, 80 to $<100 \mathrm{~kg}$ qw, $2100 \mathrm{~kg} \mathrm{qw}$ ).

Conclusions: In patients who achieved low disease activity with TCZ + MTX $\mathrm{MRI}$ changes were minimal and showed no difference in the response of active intra-articular inflammation in patients who discontinued MTX vs those who continued TCZ + MTX within the period of observation, consistent with the result of similar mean change in DAS28 between the groups in the primary analysis.

\section{REFERENCES:}

[1] Jones $\mathrm{G}$, et al. J Rheumatol 2017;44(2):142-146.

[2] Dougados M, et al. Ann Rheum Dis 2013;72(1):43-50.

[3] Strand V, et al. Arthritis Rheum 2013;65(10):2513-2523.

Acknowledgements: This study was funded by Genentech, Inc.

Disclosure of Interest: C. Peterfy Consultant for: Roche, Employee of: Spire Sciences, Inc., J. Kremer Shareholder of: Corrona, LLC, Consultant for: Abbvie, 